\title{
The effectiveness of mindfulness training on reducing the symptoms of postpartum depression
}

\author{
Hajieh Sheydaei ${ }^{1}$, Azizreza Ghasemzadeh ${ }^{2}$, Amir Lashkari ${ }^{3}$, Parvaneh Ghorbani Kajani ${ }^{4}$
}

\author{
${ }^{1}$ MA Graduate in Clinical Psychology, Maragheh University of Medical Sciences, Maragheh, Iran \\ ${ }^{2}$ Lecturer in Rehabilitation Science, Sun Face Medical Aesthetic Center, Dubai, UAE \\ ${ }^{3}$ MA Graduate in Clinical Psychology, Azad Islamic University of Roudehen, Roudehen, Iran \\ ${ }^{4}$ MA Graduate in Clinical Psychology, Azad Islamic University of Saveh, Saveh, Iran
}

\section{Type of article: Original}

\begin{abstract}
Background and Aim: Postpartum depression is one of the prevalent disorders among new mothers. The present research aimed to examine the effectiveness of mindfulness training on reducing the symptoms of postpartum depression.

Method: The present quasi-experimental research was conducted on 410 new mothers in Shahid Chamran Hospital, Tehran in 2014. Using the Beck Depression Inventory (BDI), Structured Clinical Interview and Psychological Clinical Diagnosis, 67 mothers were selected and then randomly divided into experimental and control groups, each of which with 32 applicants. Afterwards, the experimental group received mindfulness training for 8 sessions, each lasting for two hours while the control group received no training. The data were analyzed through descriptive statistics and Analysis of Covariance (ANCOVA) in SPSS, version 20.

Results: Results showed that based on Beck Inventory, the scores for the experimental group in post-test were significant $(\mathrm{p}<0.001)$, compared to those for the control group. Also, it was revealed that pre- and posttest mean scores for postpartum depression in the control group were 25.81 and 25.12 respectively while the scores for the experimental group were 24.75 and 18.5 respectively. Since the posttest mean score in the experimental group was lower than that in the pretest, it can be said that the treatment, i.e., mindfulness training, was effective in reducing depression symptoms in mothers.

Conclusion: Findings proved that mindfulness training was effective in reducing the symptoms of postpartum depression in new mothers.

Keywords: Postpartum, Depression, Mindfulness training
\end{abstract}

\section{Introduction}

Mothers consider giving birth as a valuable experience which not only affects their personal life but it affects all aspects of their social, spiritual and emotional life (1). However, pregnancy is a period which results in considerable changes in mothers' lifestyles and needs (2).In addition, the period can be a reason for many emotional concerns and psychological depressions in a mother, which requires them to be completely prepared for pregnancy physically and emotionally (3). Research studies $(4,5)$ have consistently shown that postpartum is followed by many risk factors including depression, anxiety, and stress. In other words, postpartum depression is a prevalent disorder which is experienced by many new mothers. This depression includes low self-esteem, difficult infant temperament, maternal neuroticism and irritation. Mijolla (6) defines postpartum depression as a condition in which the effects of depression, anxiety, and stressful life events can culminate to many complicated problems for mothers. The common depression of childbearing occurs in $10-15 \%$ of women following one to five weeks after delivery.

Physical problems such as obesity, sleep disturbance, low energy, irritability as well as psychological concerns such as low self-esteem, despondency, feelings of guilt and disqualification are some of the common challenges with

\section{Corresponding author:}

Hajieh Sheydaei, Maragheh University of Medical Sciences, Maragheh, Iran.

Tel: +98. 9331332853, Email: Sheydaeipsy@gmail.com

Received: June 11, 2016, Accepted: March 08, 2017, Published: July 2017

iThenticate screening: January 27, 2017, English editing: May 12, 2017, Quality control: May 18, 2017

(C) 2017 The Authors. This is an open access article under the terms of the Creative Commons Attribution-NonCommercialNoDerivs License, which permits use and distribution in any medium, provided the original work is properly cited, the use is non-commercial and no modifications or adaptations are made. 
which new mothers face. Some of the postpartum depression symptoms are increased in appetite and overweightness. Irritability, aggressive behavior, panic attacks, seclusion, and uncontrolled crying are other symptoms of postnatal depression. Maternity blues are the most outstanding symptom of postpartum depression which is considered the direct result of mothers' anger and irritation (7). The pathological research on postnatal depression proved that the disorder can be attributed to some influential factors such as unplanned/unwanted pregnancy (7), mother and baby's hospitalization (7), primary pregnancy and its type (8), low level of maternal support (9), and history of psychiatric disorder in the family (10). Furthermore, antenatal depression is a tool to predict the likelihood of developing postnatal depression (11). The prevalence of postpartum depression has been reported to be 30 to $40 \%$ in Iran $(12,13)$. Research through Beck Inventory in Kerman reported the prevalence of postpartum depression as $31.1 \%$ while the statistic for Canada was $6.2 \%$ (14). Research findings (15) indicated the frequency of depression measured through Edinburgh Postnatal Depression Scale (EPDS) in Iran, Turkey, Canada and North Carolina as $35.1 \%, 27 \%, 20 \%$ and $35 \%$ respectively. A lot of research has (16-18) examined the effectiveness of mindfulness on reducing the symptoms of depression and other psychiatric problems such as behavioral disorders (19), suicidal behavior (20), and drug abuse (21). Mindfulness has become increasingly prevalent in psychology over the past few decades. The concept of mindfulness originates from Buddhism and involves the practice of meditation to develop the skill of mindfulness, which has been described as an awareness of being aware, as well as "moment-by-moment awareness" (22). The Buddhist definition of mindfulness states that it "requires both attention and concentration to be present in the current moment" and results in a more objective view of the process of experience (22). Some of the characteristics of mindfulness can be enumerated as a nonreactive and non-judging behavior and manner as well as kindness from moment to moment (23). Gunaratana (24) defines mindfulness as a set of old spiritual traditions which go beyond suffering, and decrease the pain and unpleasantness. Therefore, mindfulness enables man to overcome the challenges through making us deeply aware of our own thoughts (16). According to some research (23), mindfulness means paying attention in a particular way, purposefully, in the present moment, and non-judgmentally. Mindfulness-Based Cognitive Therapy (MBCT) is focused on an appropriate training which is aimed at becoming aware of mental habits, emotions and internal feelings. The present research aims to study the effectiveness of mindfulness training on reducing the symptoms of postpartum depression (25).

\section{Material and Methods}

\subsection{Research design and sampling}

The present quasi-experimental research was conducted on 410 new mothers in Shahid Chamran Hospital, Tehran, Iran in 2014. The population included a total number of 410 conveniently selected applicants among mothers with some conditions including: taking psychiatric medications, suffering from serious physical illnesses and scoring 14 or higher in the Beck Depression Inventory (BDI). Afterwards, 67 applicants were recognized as having symptoms of depression, who were randomly divided into experimental and control groups (each of which with 16 persons). The experimental group received treatment, i.e. the mindfulness training for eight weeks whereas the control group received no treatment.

\subsection{Measurement tools}

To gather the data, Beck's Depression Inventory- second edition (BDI-II) was employed. The inventory is a 21 -item scale which is multiple-choice self-report inventory intended to assess the existence and severity of symptoms of depression. Also, there is a four-point scale for each item ranging from 0 to 3 . The Cronbach's alpha for outpatients and college students was reported as 0.92 and 0.93 respectively (26), which show that the scale is considered acceptable for Iranian samples (27).

\subsection{Procedure}

Explanation of MBCT consisted of eight sessions as follows:

Session 1:

The session was aimed to increase patients' awareness and accuracy through eating some raisins; also, they were expected to speak about the characteristics and specific features by participating in a pretest.

Session 2:

The purpose of the session was to train the applicants how to deal with and tackle the barriers through body scan practice and feeling meditation as well as thought exercises. 
Session 3:

The session was aimed at familiarizing the patients with mindfulness of breathing and behavior of the mind. Stretching and breath movement in addition to a three-minute breathing space were the main structures of the session.

Session 4:

The purpose of the session was to offer a way to stay in the present through sitting and walking meditation. Also, three-minute breathing was employed in order to make applicants aware of feelings and thoughts in order to overcome unpleasant experiences.

Session 5:

The session was aimed at bringing patients to the understanding that experiences can be as they are, without judging them or trying to make them different. In fact, they were encouraged to accept the experiences even if they did not like them. Sitting meditation (or sitting with the difficult), a three-minute breathing space, and reading poems were the structures for the session.

Session 6:

The session was aimed at suggesting that thoughts are not facts, thus sitting meditation along with the breathing space were some of the points which could help us stand back from our thoughts by recognizing the proper patterns. Session 7:

The session was aimed at the question "how can I best take care of myself?" To do so, taking a breathing space and deciding on what action to take, played a crucial role in answering the question.

Session 8:

The session was devoted to using what the applicants had learned to deal with future moods. It is to be mentioned here that regular mindfulness practice is important in maintaining balance in life. At the end of the session, homework review and posttest were implemented.

\subsection{Data analysis}

As said before, the selected applicants possessed conditions such as taking psychiatric medications, suffering from serious physical illnesses and scoring 14 or higher in the Beck Depression Inventory (BDI). Considering this issue, descriptive statistical methods and covariance analysis were applied to analyze acquired data by IBM( SPSSC Statistics version 20 (IBM@ Corp., Armonk, NY, USA).

\section{Results}

Hypothesis: mindfulness therapy has an impact on reducing postpartum depression. The results of Table 1 show that pre- and posttest mean scores for postpartum depression in the control group were 25.81 and 25.12 respectively while the scores for the experimental group were 24.75 and 18.5 respectively. Since the posttest mean score in the experimental group was lower than that in the pretest, it can be said that the treatment, i.e., mindfulness training, was effective in reducing depression symptoms in mothers. The results of ANCOVA (Table 2) shows that the significance level is lower than 0.01 , thus the mindfulness training was effective in reducing postpartum depression in mothers with newborns regarding the fact that depression decreased in the experimental group.

Table 1. Central tendency and score variation indicators of Beck's questionnaire related to both groups

\begin{tabular}{|l|l|l|l|l|l|}
\hline Group name & Test & Mean & Standard deviation & Min & Max \\
\hline \multirow{2}{*}{ Control } & Pre-test & 25.812 & 3.015 & 19 & 31 \\
\cline { 2 - 6 } & Post-test & 25.125 & 2.895 & 20 & 30 \\
\hline \multirow{2}{*}{ Test } & Pre-test & 24.750 & 3.065 & 18 & 30 \\
\cline { 2 - 6 } & Post-test & 18.500 & 2.280 & 15 & 23 \\
\hline
\end{tabular}

Table 2. Summary of covariance analysis to evaluate the effect of MBCT on the score of postpartum depression

\begin{tabular}{|l|l|l|l|l|l|}
\hline Source & SS & df & MS & F & Sig. \\
\hline Pre- test & 150.320 & 12 & 12.527 & 4.220 & 0.003 \\
\hline CBT & 10116.801 & 1 & 10116.801 & 3408.221 & 0.000 \\
\hline Error & 53.430 & 18 & 2.968 & - & - \\
\hline
\end{tabular}

\section{Discussion}

The findings revealed that mindfulness training was effective in reducing mothers' postpartum depression, which can be attributed to the fact that mindfulness provides mothers with a type of awareness which gives them some valuable information about destructive events such as burdens, sleep disorders and so on. Peters et al. (28) discussed 
that such training activities prevent negative behavior and emotions; in addition, mindfulness training facilitates mothers' concentration on experiences, which enables them to control their feelings especially those negative ones such as feelings of guilt and worthlessness (29). Since hormonal events of pregnancy and childbirth can be considered as a source of postpartum disorder, mindfulness training paves the way for reducing the physical and emotional impacts of depression by raising its awareness of psychological conditions. This finding is in line with those of other research $(12,18,27)$. Regarding the findings, it can be claimed that mindfulness training could reduce depression symptoms in women with newborns. This finding is in line with that of other research $(26,30-35)$, which has reached the conclusion that depression symptoms can be reduced through mindfulness training. The findings can be related to the fact that postpartum depression is mainly due to the fundamental changes that happen in a mother's life after giving birth. Taking into account the low age at marriage in some areas of Iran, it can be said that some mothers are not mentally or physically prepared to take on maternal responsibilities. These sorts of challenges can impose the feelings of disqualification and depression upon mothers. In addition, it was revealed that there was a significant relationship between mothers' education and the extent of postpartum depression. For example, mothers with diplomas may experience more depression symptoms compared to those with higher degrees. Therefore, this finding can be indicative of the fact that mothers with lower degrees are less aware of their new personal and social roles in their lives $(36,37)$. Mindfulness, on the other hand, can facilitate mothers' adjustment to the challenging situations, and contribute to their coping with some depression and other similar symptoms such as insomnia, disqualification, irresponsibility and so on. Mindfulness-based interventions appear to be useful for treating a range of disorders, including those in which impulsive behavior is a significant component. Mindfulness skills may reduce impulsivity in several ways. Improving awareness of internal experiences may facilitate monitoring of impulses and reduction of impulsive behavior, which is characterized by a lack of reflection and thoughtful intention (28). It should be mentioned that mindfulness can help parents consciously adjust their behavior, reduce the problems related to the psychological aspects in mothers and minimize the anxiety in mothers with newborns to a large extent. Mindfulness training, furthermore, can bring about some reduction in depression and anxiety by not considering every stressful event in their life as a disaster (38).

\section{Conclusions}

Results showed that mindfulness training could considerably reduce depression symptoms in women with newborn babies. Therefore, it is recommended that training should be employed in postnatal treatment. In other words, mindfulness training can be used instead of psychiatric treatment. In addition, it is suggested that mindfulness treatment can be used as an instrument in treatment approaches to postpartum depression symptoms. It is recommended that the research is further conducted in other provinces in Iran as well as on other age groups or the third child. In addition, we can implement the methodology of the present research along with other treatment methods such as pharmacotherapy.

\section{Acknowledgments:}

The author would like to thank the support staff and patients of the Shahid Chamran Hospital in Tehran, Iran. Also, it is to be noted that this research received no specific grant from any funding agency in the public, commercial, or not-for-profit sectors.

\section{Conflict of Interest:}

There is no conflict of interest to be declared.

\section{Authors' contributions:}

All authors contributed to this project and article equally. All authors read and approved the final manuscript.

\section{References:}

1) Karaçam Z, Ançel G. Depression, anxiety and influencing factors in pregnancy: a study in a Turkish population. Midwifery. 2009; 25(4): 344-56. doi: 10.1016/j.midw.2007.03.006. PMID: 17935843.

2) Orshan SA. Maternity, newborn, and women's health nursing: comprehensive care across the lifespan. Lippincott Williams \& Wilkins; 2008.

3) Lees C, McCartan G, Reynolds K. Pregnancy and birth: Your questions answered. Penguin; 2007.

4) Gale S, Harlow BL. Postpartum mood disorders: a review of clinical and epidemiological factors. J Psychosom Obstet Gynaecol. 2003; 24(4): 257-66. doi: 10.3109/01674820309074690. PMID: 14702886. 
5) Tannous L, Gigante LP, Fuchs SC, Busnello ED. Postnatal depression in Southern Brazil: prevalence and its demographic and socioeconomic determinants. BMC psychiatry. 2008; 8: 1. doi: 10.1186/1471-244X-81. PMID: 18173833, PMCID: PMC2265281.

6) De Mijolla A. International dictionary of psychoanalysis. Thomson Publ; 2005.

7) Mallikarjun PK, Oyebode F. Prevention of postnatal depression. J R Soc Promot Health. 2005; 125(5): 2216. doi: 10.1177/146642400512500514. PMID: 16220736.

8) Zanganeh M, Shams N, Alizadeh K, Rezaei M, Pormher S. Postpartum depression and its relationship with unwanted pregnancy and baby gender. Journal of Kurdistan University of Medical Sciences. 2009; 14: 6571.

9) Thompson JF, Roberts CL, Currie M, Ellwood DA. Prevalence and persistence of health problems after childbirth: associations with parity and method of birth. Birth. 2002; 29(2): 83-94. doi: 10.1046/j.1523536X.2002.00167.x. PMID: 12051189.

10) Farzad M, SB GM. Association between type of delivery and maternal blue. Journalof Shahid Beheshti University of Medical Sciences. 2005; 29(4): 331-5.

11) van Bussel JC, Spitz B, Demyttenaere K. Anxiety in pregnant and postpartum women. An exploratory study of the role of maternal orientations. J Affect Disord. 2009; 114(1): 232-42. doi: 10.1016/j.jad.2008.07.018. PMID: 18793805.

12) Ghaffarinejad AR, Khobyyari F, Pouya F. Prevalence of postpartum depression in Kerman. Iranian J Psych Clin Psychol. 2007; 17(18): 24-9.

13) Kheirabadi GR, Maracy MR, Barekatain M, Salehi M, Sadri GH, Kelishadi M, et al. Risk factors of postpartum depression in rural areas of Isfahan Province, Iran. Arch Iran Med. 2009; 12(5): 461 -7. PMID: 19722767.

14) Inandi T, Elci OC, Ozturk A, Egri M, Polat A, Sahin TK. Risk factors for depression in postnatal first year, in eastern Turkey. Int J Epidemiol. 2002; 31(6): 1201-7. doi: 10.1093/ije/31.6.1201. PMID: 12540723.

15) Evins GG, Theofrastous JP, Galvin SL. Postpartum depression: a comparison of screening and routine clinical evaluation. Am J Obstet Gynecol. 2000; 182(5): 1080-2. doi: 10.1067/mob.2000.105409. PMID: 10819833.

16) Grossman P, Niemann L, Schmidt S, Walach H. Mindfulness-based stress reduction and health benefits: A meta-analysis. J Psychosom Res. 2004; 57(1): 35-43. doi: 10.1016/S0022-3999(03)00573-7. PMID: 15256293.

17) Williams JM. Mindfulness, depression and modes of mind. Cognitive Therapy and Research. 2008; 32(6): 721-33. doi: 10.1007/s10608-008-9204-z.

18) Baer RA. Mindfulness training as a clinical intervention: A conceptual and empirical review. Clinical psychology: Science and practice. 2003; 10(2): 125-43. doi: 10.1093/clipsy.bpg015.

19) Speca M, Carlson LE, Goodey E, Angen M. A randomized, wait-list controlled clinical trial: the effect of a mindfulness meditation-based stress reduction program on mood and symptoms of stress in cancer outpatients. Psychosom Med. 2000; 62(5): 613-22. doi: 10.1097/00006842-200009000-00004. PMID: 11020090.

20) Linehan MM, Armstrong HE, Suarez A, Allmon D, Heard HL. Cognitive-behavioral treatment of chronically parasuicidal borderline patients. Arch Gen Psychiatry. 1991; 48(12): 1060-4. doi: 10.1001/archpsyc.1991.01810360024003. PMID: 1845222.

21) Dabbaghi P, Asgharnejad Farida AA, Atef-Vahidb MK, Bolharic J. Effectiveness of group cognitive therapy based on mindfulness and spiritual schema activation in the prevention of opioid abuse relapse. Iranian Journal of Psychiatry and Clinical Psychology. 2008; 13(4): 366-75.

22) Hirst IS. Perspectives of mindfulness. J Psychiatr Ment Health Nurs. 2003; 10(3): 359-66. doi: 10.1046/j.1365-2850.2003.00610.x. PMID: 12755922.

23) Kabat - Zinn J. Mindfulness - based interventions in context: past, present, and future. Clinical psychology: Science and practice. 2003; 10(2): 144-56. doi: 10.1093/clipsy.bpg016.

24) Gunaratana B, Gunaratana H. Mindfulness in plain English. Simon and Schuster; 2011.

25) Crane R. Mindfulness-based cognitive therapy: Distinctive features. Routledge; 2013.

26) Mohammad-Khani P, Dabsoun K, Hosseini F, Momeini F. Comparison of the Effectiveness MindfulnessBased Cognitive Therapy and Cognitive-Behavior Therapy and Treatment as Usual on Depression and Additional Symptoms and Other Psychiatric Symptoms. Journal of Clinical Psycology. 2011; 3(1): 19-26.

27) Khoshnam S, Borjali A, Karegari-padar L, Amiri H. Effectiveness of emotion-focused therapy on patients with major depression disorder. Contemporary Psychology. 2014; 9(1): 95-106. 
28) Peters JR, Erisman SM, Upton BT, Baer RA, Roemer L. A preliminary investigation of the relationships between dispositional mindfulness and impulsivity. Mindfulness. 2011; 2(4): 228-35. doi: 10.1007/s12671011-0065-2.

29) Malekpour N. Psychometric properties of the five factors of mindfulness questionnaire. [dissertation]. Islamic Azad University of Marvdasht. 2012.

30) Ghadam Pour E, Azizi A, Mohamadi J. The Efficacy of Detached Mindfulness in Meta-Cognitive Therapy on Postpartum Depression. Journal of Nursing Education. 2016; 5(5): 17-22. doi: 10.21859/jne-05053.

31) Klainin-Yobas P, Cho MA, Creedy D. Efficacy of mindfulness-based interventions on depressive symptoms among people with mental disorders: a meta-analysis. Int J Nurs Stud. 2012; 49(1): 109-21. doi: 10.1016/j.ijnurstu.2011.08.014. PMID: 21963234.

32) Britton WB, Shahar B, Szepsenwol O, Jacobs WJ. Mindfulness-based cognitive therapy improves emotional reactivity to social stress: results from a randomized controlled trial. Behav ther. 2012; 43(2): 365-80. doi: 10.1016/j.beth.2011.08.006. PMID: 22440072, PMCID: PMC3495556.

33) Peterson BD, Eifert GH. Using acceptance and commitment therapy to treat infertility stress. Cognitive and Behavioral Practice. 2011; 18(4): 577-87. doi: 10.1016/j.cbpra.2010.03.004.

34) Lustyk MK, Gerrish WG, Douglas H, Bowen S, Marlatt GA. Relationships among premenstrual symptom reports, menstrual attitudes, and mindfulness. Mindfulness (N Y). 2011; 2(1): 37-48. doi: 10.1007/s12671011-0041-x. PMID: 27162560, PMCID: PMC4859870.

35) Baer RA, Walsh E, Lykins EL. Assessment of mindfulness. In Clinical handbook of mindfulness. New York: Springer; 2009: 153-168.

36) Shabiri F, Farhadi Nasab A, Nazari M. Detecting postpartum depression in referents to medical and health centers in Hamadan city. Sci J Hamadan Univ Med Sci. 2007; 14(3): 24-8.

37) Sehati Shafaei F, Rangbar Kouchaksaraei F, Ghoujazadeh M, Mohammad Rezaei ZH. Study of relationship between some predisposing factors and postpartum depression. J Ardabil Univ Med Sci. 2008; 8(1): 54-61.

38) Wells A, Colbear JS. Treating posttraumatic stress disorder with metacognitive therapy: a preliminary controlled trial. J Clin Psychol. 2012; 68(4): 373-81. doi: 10.1002/jclp.20871. PMID: 24469928. 